\title{
BMJ Open Single group multisite safety trial of sibling cord blood cell infusion to children with cerebral palsy: study protocol and rationale
}

\author{
Kylie Crompton (D) , ${ }^{1,2,3}$ Iona Novak, ${ }^{4}$ Michael Fahey, ${ }^{5,6}$ Nadia Badawi, ${ }^{4,7}$ \\ Euan Wallace (D) , ${ }^{8}$ Katherine Lee, ${ }^{3,9}$ Francoise Mechinaud-Heloury, ${ }^{10}$ \\ Paul B Colditz, ${ }^{11}$ Ngaire Elwood, ${ }^{3,12}$ Priya Edwards, ${ }^{13,14}$ Dinah Reddihough ${ }^{1,2,3}$
}

To cite: Crompton K, Novak I, Fahey M, et al. Single group multisite safety trial of sibling cord blood cell infusion to children with cerebral palsy: study protocol and rationale. BMJ Open 2020;10:e034974. doi:10.1136/ bmjopen-2019-034974

- Prepublication history and additional material for this paper are available online. To view these files, please visit the journal online (http://dx.doi org/10.1136/bmjopen-2019034974).

Received 14 October 2019 Revised 10 December 2019 Accepted 04 February 2020
D) Check for updates

(C) Author(s) (or their employer(s)) 2020. Re-use permitted under CC BY-NC. No commercial re-use. See rights and permissions. Published by BMJ.

For numbered affiliations see end of article.

Correspondence to Dr Kylie Crompton;

kylie.crompton@mcri.edu.au

\section{ABSTRACT}

Introduction Cerebral palsy (CP) is the most common physical disability of childhood but has no cure. Stem cells have the potential to improve brain injury and are proposed as a therapy for CP. However, many questions remain unanswered about the most appropriate cell type, timing of infusions, dose required and associated risks. Therefore, human safety and efficacy trials are necessary to progress knowledge in the field.

Methods and analysis This is a single group study with sample size $n=12$ to investigate safety of single-dose intravenous 12/12 human leucocyte antigen-matched sibling cord blood cell infusion to children with CP aged $1-16$ years without immune suppression. The study is similar to a $3+3$ design, where the first two groups of participants have severe $\mathrm{CP}$, and the final six participants include children with all motor severities. Children will be monitored for adverse events and the duration that donor cells are detected. Assessments at baseline, 3 and 12 months will investigate safety and preliminary evidence of change in gross motor, fine motor, cognitive and quality of life outcomes.

Ethics and dissemination Full approval was obtained from The Royal Children's Hospital Human Research Ethics Committee, and a clinical trial notification was accepted by Australia's Therapeutic Goods Administration. Participant guardian informed consent will be obtained before any study procedures. The main results of this study will be submitted for publication in a peer-reviewed journal. Trial registration number ACTRN12616000403437, NCT03087110.

\section{INTRODUCTION}

\section{Cerebral palsy}

Cerebral palsy (CP) describes a group of permanent non-progressive motor and postural disorders arising from damage to the developing brain while in utero, during birth or in the first years of life, ${ }^{12}$ and affects around 2 per 1000 live births across the world. ${ }^{3}$ Depending on the location and severity of brain damage, different regions of the body may be affected. The main types
Strengths and limitations of this study

- This is a rigorous safety study of a potential stem cell intervention for children with cerebral palsy.

- An advantage of the study is the investigation to determine cell persistence in immune-competent patients' circulation, which is relevant to many patient groups.

- However, as this is a safety study, the sample size is small, using a heterogeneous participant population.

of motor disorder found in CP include spasticity (stiffness of muscles accounting for around $80 \%$ of all diagnoses), dyskinesia (abnormal involuntary movements) and ataxia (unsteadiness) which result from lack of normal nervous control of muscles. ${ }^{1}$

CP may be classified by the distribution of impairment: hemiplegia indicates that one side of the body is affected, diplegia that the legs greater than arms are affected and quadriplegia involves all four limbs and often the trunk. The degree of motor impairment is often defined using the Gross Motor Function Classification System (GMFCS), with GMFCS I describing a mildly impaired child able to walk independently, increasing in severity to GMFCS V indicating limited motor function and wheelchair use with poor head control. ${ }^{4}$ $\mathrm{CP}$ is often associated with epilepsy, difficulties in speech, sight, hearing, sensation, perception, behaviour or cognition. There is currently no cure for CP.

\section{Cord blood for CP}

Recent interest in stem cell therapy for intractable neurological disorders has led to a large number of preclinical studies of brain injuries related to $\mathrm{CP}$ that show evidence of therapeutic potential. Human umbilical cord blood (UCB) was used as the source of stem 
cells as it is less ethically complex than other sources. UCB has been shown to be therapeutically useful and contains a variety of multipotent stem cells and other active cell types. The stem cells in UCB do not lead to cancers and present a lower risk of graft-versus-host disease ( $\mathrm{GvHD})$ than bone marrow stem cells. ${ }^{5}$ Transplantation of UCB cells in acute animal models of $\mathrm{CP}$ such as excitotoxic white matter injury ${ }^{6}$ and neonatal hypoxia-ischaemia ${ }^{7-12}$ has shown significant neurofunctional improvement, as have models of adult stroke, ${ }^{13-18}$ spinal cord injury ${ }^{19-23}$ and traumatic brain injury. ${ }^{24}$ While some studies involve transplanting umbilical cord blood cells (UCBC) directly to the injured area of the brain, there is evidence that the minimally invasive intravenous infusion to the periphery is equally as effective. ${ }^{625}$ Because peripherally administered human (xenogeneic) stem cells do not engraft to replace lost brain cells in immune-suppressed animal models, such stem cell treatment is conceptualised best as a transfusion, not a transplant.

Investigations into the mechanism of action of UCBC infusion reveal (A) decreased astrogliosis and neuronal apoptosis $^{26}{ }^{27}$; (B) increased white matter injury repair $^{8829}$; (C) angiogenesis ${ }^{12} 30$; and (D) enhancement of endogenous neural stem cell proliferation. ${ }^{31}{ }^{32} \mathrm{CP}$ is a heterogeneous condition with varied brain pathology, and stem cell infusion may act through different mechanisms for different children. ${ }^{31} 3334$ Preclinical work has focused mainly on acute brain injury, which involves inflammation, primary and secondary cell death and chemical signalling, and it is unknown if these transfusion mechanisms will operate in the same way in the chronic phase of disease.

\section{Safety considerations}

Autologous blood transfusions are immunologically safe, while allogeneic cell infusions introduce the risk of an immune response. The first use of allogeneic UCBC infusion was a transplant in $1989,{ }^{35}$ and after optimising the technique in immune-depleted conditions for 25 years, there is still a risk of mortality from GvHD, whereby the donor cells attack the immune-suppressed recipient. This risk is at its lowest when using fully human leucocyte antigen (HLA)-matched related donors. ${ }^{5}$ Generic HLA matching examines six HLA genes and requires a minimum of 4/6 HLA match depending on clinical context, however technology allows examination of additional HLA genes.

The preclinical data behind stem cell therapy as a possible treatment for $\mathrm{CP}$ demonstrate that donor UCBCs may not need to persist or engraft to mediate functional benefit. ${ }^{7}$ Given the risks and side effects, and little expected benefit, this protocol does not use a conditioning regimen or immune suppression. Without immune suppression, the recipient's immune system is expected to easily reject infused cells, further reducing the risk of GvHD.

There is a risk of nausea, anaphylaxis and cardiovascular side effects when a cryopreservant such as dimethyl sulfoxide is required which will be mitigated by 'washing' the cord blood unit before infusion. ${ }^{36}$ There is also a risk as with any intravenous cell infusion that pulmonary capillaries may temporarily become blocked, ${ }^{37}$ although this is less likely with cord blood or bone marrow mononuclear cells than larger types of stem cell. ${ }^{38}$ These adverse events (AE) are considered temporary and treatable. ${ }^{3637}$

\section{Rationale for phase I study}

Despite the lack of conclusive evidence, UCBC infusion for CP is already in use in some parts of the world. Moreover, Australian children with CP are travelling to different parts of the world to undergo UCBC therapy in an unregulated environment and at a great financial cost. $^{39}$ Therefore, well-designed and properly administrated trials evaluating the safety and efficacy of UCBCs in $\mathrm{CP}$ are necessary to guide clinicians and to inform patients and their families; and if successful, to develop treatment programmes in Australia. Such treatments would ideally involve cells that are available to any child with $\mathrm{CP}$, yet this must be balanced against the increasing risk profile of cells taken from unrelated donors when there is as yet little evidence of benefit. For the same reasons, the method of administration must be designed to reduce risk wherever possible. A recent systematic review and metaanalysis of controlled trials of stem cells used for children with CP found five trials that met criteria, studying four different types of stem cells (fetal and bone marrowderived neural stem cells, olfactory ensheathing cells and allogeneic UCBCs; all cryopreserved) at doses ranging from $2 \times 10^{6}$ cells in total to $\geq 3 \times 10^{7}$ cells $/ \mathrm{kg}$. The analysis indicated an acceptable risk-benefit ratio of $3 \%$ AEs in CP stem cell recipients and 2\% AEs in controls and a small intervention effect on gross motor skills. ${ }^{40}$ This study aims to investigate safety in cryopreserved washed 12/12 HLAmatched sibling UCBCs, intravenously infused without immune suppression.

\section{METHODS}

\section{Aims and objectives}

Primary objective

The primary objective of this study is to gain preliminary information on the safety of 12/12 HLA-matched sibling UCBC infusion in children with CP.

\section{Secondary objectives}

The secondary objectives of this study are:

A. To gain preliminary information on the treatment effect of 12/12 HLA-matched UCBC infusion relative to baseline.

B. To better understand the length of time that infused matched sibling UCBCs remain within recipients.

C. To gather information and samples for future studies into the mechanistic activity of UCBCs. 


\begin{tabular}{lll}
\hline Table 1 & Participant cohorts within & \\
\hline Cohort & Participants, $\mathbf{n}$ & type design \\
\hline 1 & 3 & Burden of disease \\
\hline 2 & 3 & Severe CP \\
3 & 6 & Severe CP \\
\hline
\end{tabular}

$\mathrm{CP}$, cerebral palsy.

\section{Study design}

Multisite single group investigator-initiated safety study conducted in tertiary hospitals. Rather than dose escalation, a 3+3 type design, with independent safety review by an independent Data Safety Monitoring Board (DSMB) between each group of 3 to assess the ongoing ethical acceptability of the study. After the first 3+3 participants with severe CP, the DSMB will decide whether the study can include a reduced burden of disease and continue with the final six participants having CP of any severity (see table 1). Any indication of GvHD severe enough to require intervention will stop the study.

\section{Safety}

The role of the DSMB is to safeguard the interests of trial participants by monitoring safety throughout the trial, trial feasibility and, together, advise Trial Steering Committee and Human Research Ethics Committee (HREC) on continuing ethical acceptability. The fivemember DSMB will comprise transplant, paediatric, rehabilitation, biostatistical and clinical trials expertise and will require a minimum of three members to make decisions according to the trial DSMB Charter.

AEs will be recorded from the time of infusion until the last visit (12 months after infusion) regardless of their association with the study. The study team will estimate the likelihood that the $\mathrm{AE}$ was the result of the study intervention as unrelated, possible, probable or definite, according to the timing of the AE relative to the cell infusion, whether the $\mathrm{AE}$ is a known response to infusion, or could have occurred as part of the participant's clinical status or environment.

Serious adverse events (SAEs) will be reported to the DSMB within 72 hours of notification regardless of relatedness. The DSMB will provide independent advice on relatedness and evaluate the study team's response to the SAE (designation as suspected unexpected serious adverse reaction or significant safety issue, or requirement of urgent safety measure, all of which will be reported to the local HREC within 72 hours). The DSMB has the power to suspend or cease the trial, and detection of GvHD of a severity that requires treatment will automatically stop the trial.

\section{Subject/study population}

Inclusion criteria

To be eligible for this study, the following criteria must be fulfilled:
- Aged older than 1 year and younger than 16 years at the time of enrolment.

- Diagnosis of CP as confirmed by paediatrician and physiotherapist study team members.

- 12/12 HLA-matched sibling cord blood unit (CBU) in storage at a Therapeutic Goods Administration (TGA) licensed private cord blood bank.

- Ability to travel to one of the trial centres and participate in assessments.

- Informed consent by parent/guardian and an indication of willingness/compliance by the children.

\section{Exclusion criteria}

Patients will be unable to participate in the trial if:

- They show presence of progressive neurological disease.

- They have a known genetic disorder.

- They have a known brain dysplasia.

- They have ever been diagnosed with an immune system disorder or immune deficiency syndrome.

- They have infectious disease markers on virology screen (HIV 1 and 2 antibody and nucleic acid testing (NAT), hepatitis B core antibody, surface antigen and NAT, hepatitis $\mathrm{C}$ antibody and NAT, human T-cell lymphotropic 1 and 2 antibody, cytomegalovirus (CMV), syphilis).

- The intended cord blood unit shows evidence of contamination or has fewer than $10^{7}$ nucleated cells per kilogram of body mass.

- They require ventilator support.

- They are unwell, or if the participant's medical condition does not allow safe travel.

- They have previously undertaken any form of cell therapy.

- They have had, or are scheduled for, treatment with botulinum toxin A within 3 months before or after infusion.

- They have had, or are scheduled for, surgery within 3 months before or after infusion.

- They cannot obtain parental or guardian consent.

\section{Enrolment and screening}

The study will be advertised through private Australian cord blood banks, clinical trial registries, CP professional and community organisations and institutional websites. When families of children with CP approach the study team with evidence of sibling cord blood unit in storage, they are provided with full information and invited to an informed consent discussion. Once written parent/guardian consent is obtained, and optional consent for extended use of biological samples is considered (sample consent form in online supplementary material), screening for HLA match is undertaken. A $75 \%$ screen fail rate is expected due to HLA mismatch, and no other eligibility screening is undertaken until this result is available (see table 2).

\section{Intervention}

The intervention will take place as a day procedure within a tertiary hospital paediatric haemopoietic stem cell 
Table 2 Schedule of assessments

\begin{tabular}{|c|c|c|c|c|c|c|c|c|c|}
\hline Study phase & Screening & Baseline & Infusion & Follov & -up & & & & \\
\hline Timing & $\begin{array}{l}>8 \text { weeks } \\
\text { prior to } \\
\text { infusion }\end{array}$ & $\begin{array}{l}28 \text { days prior } \\
\text { to infusion }\end{array}$ & 0 & 1 day & 1 week & $\begin{array}{l}1 \\
\text { month }\end{array}$ & $\begin{array}{l}3 \\
\text { months }\end{array}$ & $\begin{array}{l}6 \\
\text { months }\end{array}$ & $\begin{array}{l}12 \\
\text { months }\end{array}$ \\
\hline Informed consent & $x$ & & & & & & & & \\
\hline Medical history, CP assessment & & $x$ & & & & & & & \\
\hline Medical examination, adverse events & & $x$ & $x$ & $x$ & $\mathrm{X}$ & $x$ & $x$ & $x$ & $x$ \\
\hline Upper limbs assessment & & $x$ & & & & & $\mathrm{x}$ & & $\mathrm{x}$ \\
\hline Quality of life assessment & & $x$ & & & & & $\mathrm{x}$ & & $\mathrm{x}$ \\
\hline Cognition assessment & & $\mathrm{X}$ & & & & & & & $\mathrm{x}$ \\
\hline Infusion of UCBCs & & & $x$ & & & & & & \\
\hline
\end{tabular}

$\mathrm{CP}$, cerebral palsy; UCBC, umbilical cord blood cell.

transplant ward to ensure appropriate expertise. After peripheral venous cannulation, the patient will receive intravenous normal saline for 2 hours along with hydrocortisone, antihistamine, paracetamol and ondansetron to reduce risk of adverse infusion reactions.

Cryopreserved UCBCs previously collected, tested for standard infectious disease markers (HIV, hepatitis B and $\mathrm{C}$, human T-cell lymphotropic virus, CMV, syphilis), aerobic and anaerobic microbiology contamination/ sterility and cell count, and stored in the gaseous phase of liquid nitrogen by a licensed cord blood bank are pilot thawed by the storage facility before shipment, checked on arrival at the Cell Therapy Laboratory and washed and resuspended in dextran/albumin to a volume of 100 $\mathrm{mL}$. Cell viability, characterisation of CD34+ and CD45+ fraction and sterility are assessed on both pilot thaw and the final product. Infusion must be completed within 1 hour of thaw: infusion by gravity for $5 \mathrm{~min}$, then paused to assess immediate safety before continuing. Minimum cell dose of $10^{7}$ total nucleated cells $/ \mathrm{kg}$ is based on pilot thaw cell counts and was selected based on preclinical data and international trials at the time of ethics submission. Normal saline is provided for an additional 4 hours after infusion, and intramuscular rhesus D immunoglobulin provided if donor/recipient is a rhesus mismatch. Vital signs and AEs will be monitored, and the patient discharged if medically stable.

\section{Treatment discontinuation}

Treatment administration is a single dose; therefore, interruption or discontinuation will only occur in response to immediate infusion reactions. Infusion will initially be interrupted, and continued if safe, but discontinued if reactions cannot easily be treated.

\section{Endpoints}

Safety

The primary safety endpoint will be assessed through the number of AEs possibly related to UCBCs or infusion procedure by 36 hours, 3 months and 12 months after infusion. AEs will be elicited during observation, study visit medical reviews with transplant specialist and developmental paediatrician, laboratory tests (full blood examination, liver function tests, inflammatory markers) and between-visit reports from families. Relationship of AEs to study intervention will be assessed based on expectedness, timing relative to infusion, ongoing presence of donor DNA in the circulation, the patient's clinical state and environment.

\section{Preliminary efficacy}

Motor function will be assessed using the gold standard for CP, the Gross Motor Function Measure-66, which is valid, reliable and responsive to change ${ }^{41}$ and has population norms available. Upper limb movement will be assessed with the Quality of Upper Extremity Skills Test (QUEST), which measures each upper limb separately, then combines limb scores for each of four domains: disassociated movements, grasp, weight-bearing and protective extension. The QUEST is limited by measuring impairment reduction rather than functional activity but is one of the few bimanual assessment tools for CP with appropriate psychometric properties. ${ }^{42}$ See table 2 for the schedule of assessments.

Cognitive assessment for CP is known to be challenging due to the motor requirements, yet there is anecdotal evidence of improvements in attention and learning following stem cell transplants. The direct cognitive assessments will be age appropriate (Bayley Scales of Infant Development, Second Edition, for children aged 1-2 years; Wechsler Preschool Primary Scale of Intelligence, Fourth Edition, for children aged 2-6 years; and Wechsler Intelligence Scale for Children, Fifth Edition, for children aged 6-16 years). Additionally, the BeeryBuktenica Developmental Test of Visual-Motor Integration will be used, along with parent report versions of the Vineland Adaptive Behaviour Scales, Second Edition, Behaviour Rating Inventory of Executive Function, and the Strengths and Difficulties Questionnaire. 


\section{Donor cell persistence}

Because there is no direct evidence of the longevity of matched sibling cord blood cells after infusion to an immune-competent recipient, donor cell persistence will be examined using a highly sensitive surrogate chimerism analysis of donor DNA. The donor and the recipient will be genotyped to detect copy number deletions; then digital droplet PCR will be used to quantify the fraction of donor DNA, sensitive to 20 genome equivalents $/ \mathrm{mL} .{ }^{43}$

\section{Patient and public involvement}

A Delphi study of research priorities for CP found that stem cell research was the third highest research priority ${ }^{44}$ for the community. The CP Quest community reference group will be consulted before communication of study outcomes to ensure the messages and distribution are appropriate. No attempt was made to assess the burden of the intervention by patients themselves.

\section{Statistical analysis}

As the primary aim of this study is to assess safety, the sample size of 12 participants was selected to allow sequential groups of three participants. We will compare group characteristics with population data from the Australian Cerebral Palsy Register to assess the generalisability of the results obtained. Given the pilot nature of this trial, the results from this study will be presented descriptively. Safety data will be summarised as the proportion of participants who have an SAE and an AE within either of the three safety periods: within 36 hours, within 3 months or within the 12-month study period. The change in lab results at each time point will be presented relative to baseline on an individual participant basis, with comparison to published minimal clinically important difference of the tool. ${ }^{45}{ }^{46}$ Change in motor and cognitive function will be presented relative to baseline. Donor cell persistence data will be categorised as 'immediate rejection' to indicate return to baseline fraction of donor DNA within 24 hours; 'rejection' to indicate a return to baseline fraction of donor DNA by 1 month; 'slow rejection' to indicate the presence of between 200 donor genome equivalent $/ \mathrm{mL}$ and engraftment at 3 months, and 'engraftment'.

\section{Data management and administrative aspects}

Study data will be collected and managed using Research Electronic Data Capture (REDCap) tools hosted at Murdoch Children's Research Institute (MCRI). REDCap is a secure, web-based application designed to support data capture for research studies, providing (1) an intuitive interface for validated data entry; (2) audit trails for tracking data manipulation and export procedures; (3) automated export procedures for seamless data downloads to common statistical packages; and (4) procedures for importing data from external sources. Hard copy documents will be stored in locked files, and electronic files will be password protected and accessible by the study team only. Final data collection is predicted to occur in mid-2020. Records will be securely stored until the youngest participant turns 25 years of age, although records of biobanked samples and their consent conditions may be retained longer.

Neuroscience Trials Australia will independently verify source data and adherence to Good Clinical Practice. The study may be audited or inspected by representatives of regulatory organisations.

\section{Data statement}

The deidentified data set collected for this analysis of the this trial will be available 6 months after publication of the primary outcome. The study protocol, analysis plan and consent forms will also be available. The data may be obtained from the MCRI. Prior to releasing any data the following are required: a data access agreement must be signed between relevant parties, the SCUBI-CP Trial Steering Committee must see and approve the analysis plan describing how the data will be analysed, there must be an agreement around appropriate acknowledgement and any additional costs involved must be covered. Should the Trial Steering Committee be unavailable, this role is delegated to the MCRI. Data will only be shared with a recognised research institution which has approved the proposed analysis plan.

\section{ETHICS AND DISSEMINATION}

This study received initial approval from The Royal Children's Hospital HREC in late 2015, as have all changes to participant documents and protocol amendments. The current protocol is version 10, approved on $6 \mathrm{March}$ 2017. A clinical trial notification was submitted to the TGA, Australia, in March 2016. The study is registered on both the Australian and New Zealand Clinical Trials Registry and ClinicalTrials.gov with all items from the WHO Trial Registration Data Set and regularly updated. Recruitment is complete. Publication in a peer-reviewed journal is planned regardless of the outcome. The decision of what to publish and when, along with authorship according to Vancouver guidelines, will be made by the Trial Steering Committee. No participant will be identifiable from the data reported.

\section{Author affiliations}

${ }^{1}$ Neurodisability and Rehabilitation, Murdoch Children's Research Institute, Parkville, Victoria, Australia

${ }^{2}$ Neurodevelopment and Disability, The Royal Children's Hospital Melbourne,

Parkville, Victoria, Australia

${ }^{3}$ Paediatrics, The University of Melbourne, Melbourne, Victoria, Australia

${ }^{4}$ Cerebral Palsy Alliance Research Institute, The University of Sydney, Sydney, New

South Wales, Australia

${ }^{5}$ Paediatric Neurology, Monash Health, Clayton, Victoria, Australia

${ }^{6}$ Paediatrics, Monash University, Clayton, Victoria, Australia

${ }^{7}$ Grace Centre for Newborn Care, The Children's Hospital at Westmead, Westmead, New South Wales, Australia

${ }^{8}$ Obstetrics and Gynaecology, Monash University, Clayton, Victoria, Australia

${ }^{9}$ Clinical Epidemiology and Biostatistics Unit, Murdoch Children's Research Institute, Parkville, Victoria, Australia

${ }^{10}$ Children's Cancer Centre, The Royal Children's Hospital Melbourne, Parkville, Victoria, Australia

${ }^{11}$ Centre for Clinical Research, The University of Queensland, Brisbane, Queensland, Australia 
${ }^{12}$ Cell Biology, Murdoch Children's Research Institute, Parkville, Victoria, Australia

${ }^{13}$ Queensland Paediatric Rehabilitation Service, Children's Health Queensland Hospital and Health Service, Herston, Queensland, Australia

${ }^{14}$ Queensland Cerebral Palsy and Rehabilitation Research Centre, The University of Queensland, Brisbane, Queensland, Australia

\section{Twitter Euan Wallace @euan_wallace}

Acknowledgements The authors acknowledge Professor Mark Kirkland, OAM, of Deakin University and Cell Care Australia, Victoria, Australia, for his contribution to study design and leadership, and Professor Peter Anderson and Ms Janet Hough for their contribution to study design.

Contributors All authors provided substantial contribution to design and drafting of the manuscript. KEC: coordination of the study. FMH, NE, IN: content expertise. $\mathrm{KL}$ : biostatistical study design. DR, MCF, NB, EW, PBC, FMH, IN, KL, PE and KEC: members of the Steering Committee. DR: study lead at coordinating centre (The Royal Children's Hospital). PE: study lead at subsite (Queensland Children's Hospital).

Funding This work is generously supported by Cell Care Australia, which aided in study design and is represented on the Trial Steering Committee but will not be involved in data analysis or interpretation; and the Cerebral Palsy Alliance Research Foundation, a not-for-profit organisation that aided in study design, is represented on the Trial Steering Committee and will be involved in data interpretation and dissemination. Neither organisation can withhold publication. The study is sponsored by Murdoch Children's Research Institute.

Competing interests Cell Care Australia is a private cord blood bank with a representative on the Trial Steering Committee. There is, therefore, a potential conflict of interest which has been declared to HREC and Steering Committee and is well recognised. No one affiliated with Cell Care Australia will be involved in data analysis or interpretation.

Patient consent for publication Not required.

Ethics approval This study received initial approval from The Royal Children's Hospital Human Research Ethics Committee.

Provenance and peer review Not commissioned; externally peer reviewed.

Open access This is an open access article distributed in accordance with the Creative Commons Attribution Non Commercial (CC BY-NC 4.0) license, which permits others to distribute, remix, adapt, build upon this work non-commercially, and license their derivative works on different terms, provided the original work is properly cited, appropriate credit is given, any changes made indicated, and the use is non-commercial. See: http://creativecommons.org/licenses/by-nc/4.0/.

\section{ORCID iDs}

Kylie Crompton http://orcid.org/0000-0003-4496-7101

Euan Wallace http://orcid.org/0000-0002-4506-5233

\section{REFERENCES}

1 Rosenbaum P, Paneth N, Leviton A, et al. A report: the definition and classification of cerebral palsy April 2006. Dev Med Child Neurol Suppl 2007;109:8-14.

2 Badawi N, Watson L, Petterson B, et al. What constitutes cerebral palsy? Dev Med Child Neurol 1998;40:520-7.

3 Oskoui M, Coutinho F, Dykeman J, et al. An update on the prevalence of cerebral palsy: a systematic review and meta-analysis. Dev Med Child Neurol 2013;55:509-19.

4 Palisano R, Rosenbaum P, Walter S, et al. Development and reliability of a system to classify gross motor function in children with cerebral palsy. Dev Med Child Neurol 1997;39:214-23.

5 Rocha V, Wagner JE, Sobocinski KA, et al. Graft-Versus-Host disease in children who have received a cord-blood or bone marrow transplant from an HLA-identical sibling. Eurocord and international bone marrow transplant registry working Committee on alternative donor and stem cell sources. N Engl J Med 2000;342:1846-54.

6 Dalous J, Pansiot J, Pham H, et al. Use of human umbilical cord blood mononuclear cells to prevent perinatal brain injury: a preclinical study. Stem Cells Dev 2013;22:169-79.

7 Bae S-H, Kong T-H, Lee H-S, et al. Long-Lasting paracrine effects of human cord blood cells on damaged neocortex in an animal model of cerebral palsy. Cell Transplant 2012;21:2497-515.

8 de Paula S, Greggio S, Marinowic DR, et al. The dose-response effect of acute intravenous transplantation of human umbilical cord blood cells on brain damage and spatial memory deficits in neonatal hypoxia-ischemia. Neuroscience 2012;210:431-41.

9 Geissler M, Dinse HR, Neuhoff S, et al. Human umbilical cord blood cells restore brain damage induced changes in rat somatosensory cortex. PLoS One 2011;6:e20194.

10 Meier C, Middelanis J, Wasielewski B, et al. Spastic paresis after perinatal brain damage in rats is reduced by human cord blood mononuclear cells. Pediatr Res 2006;59:244-9.

11 Pimentel-Coelho PM, Magalhães ES, Lopes LM, et al. Human cord blood transplantation in a neonatal rat model of hypoxic-ischemic brain damage: functional outcome related to neuroprotection in the striatum. Stem Cells Dev 2010;19:351-8.

12 Rosenkranz K, Kumbruch S, Tenbusch M, et al. Transplantation of human umbilical cord blood cells mediated beneficial effects on apoptosis, angiogenesis and neuronal survival after hypoxicischemic brain injury in rats. Cell Tissue Res 2012;348:429-38.

13 Boltze J, Schmidt UR, Reich DM, et al. Determination of the therapeutic time window for human umbilical cord blood mononuclear cell transplantation following experimental stroke in rats. Cell Transplant 2012;21:1199-211.

14 Borlongan CV, Hadman M, Sanberg CD, et al. Central nervous system entry of peripherally injected umbilical cord blood cells is not required for neuroprotection in stroke. Stroke 2004;35:2385-9.

15 Chen J, Sanberg PR, Li Y, et al. Intravenous administration of human umbilical cord blood reduces behavioral deficits after stroke in rats. Stroke 2001;32:2682-8.

16 Nystedt J, Mäkinen S, Laine J, et al. Human cord blood CD34+ cells and behavioral recovery following focal cerebral ischemia in rats. Acta Neurobiol Exp 2006;66:293-300.

17 Vendrame M, Cassady J, Newcomb J, et al. Infusion of human umbilical cord blood cells in a rat model of stroke dose-dependently rescues behavioral deficits and reduces infarct volume. Stroke 2004;35:2390-5.

18 Xiao J, Nan Z, Motooka Y, et al. Transplantation of a novel cell line population of umbilical cord blood stem cells ameliorates neurological deficits associated with ischemic brain injury. Stem Cells Dev 2005;14:722-33.

19 Dasari VR, Spomar DG, Gondi CS, et al. Axonal remyelination by cord blood stem cells after spinal cord injury. J Neurotrauma 2007;24:391-410.

20 Kao C-H, Chen S-H, Chio C-C, et al. Human umbilical cord bloodderived CD34+ cells may attenuate spinal cord injury by stimulating vascular endothelial and neurotrophic factors. Shock 2008;29:49-55.

21 Park D-H, Lee J-H, Borlongan CV, et al. Transplantation of umbilical cord blood stem cells for treating spinal cord injury. Stem Cell Rev Rep 2011;7:181-94.

22 Saporta S, Kim J-J, Willing AE, et al. Human umbilical cord blood stem cells infusion in spinal cord injury: engraftment and beneficial influence on behavior. J Hematother Stem Cell Res 2003;12:271-8.

23 Zhao ZM, Li HJ, Liu HY, et al. Intraspinal transplantation of CD34+ human umbilical cord blood cells after spinal cord hemisection injury improves functional recovery in adult rats. Cell Transplant 2004;13:113-22.

24 Lu D, Sanberg PR, Mahmood A, et al. Intravenous administration of human umbilical cord blood reduces neurological deficit in the rat after traumatic brain injury. Cell Transplant 2002;11:275-81.

25 Willing AE, Lixian J, Milliken M, et al. Intravenous versus intrastriatal cord blood administration in a rodent model of stroke. J Neurosci Res 2003;73:296-307.

26 Aridas JDS, McDonald CA, Paton MCB, et al. Cord blood mononuclear cells prevent neuronal apoptosis in response to perinatal asphyxia in the newborn lamb. J Physiol 2016;594:1421-35.

27 Wasielewski B, Jensen A, Roth-Härer A, et al. Neuroglial activation and Cx43 expression are reduced upon transplantation of human umbilical cord blood cells after perinatal hypoxic-ischemic injury. Brain Res 2012;1487:39-53.

28 Paton M, McDonald C, Aridas J, et al. Umbilical cord blood stem cells: a new line of defence against cerebral palsy. J Paediatr Child Health 2015;51:96.

29 Paton MCB, Allison BJ, Li J, et al. Human umbilical cord blood therapy protects cerebral white matter from systemic LPS exposure in preterm fetal sheep. Dev Neurosci 2018;40:258-70.

30 Taguchi A, Soma T, Tanaka H, et al. Administration of CD34+ cells after stroke enhances neurogenesis via angiogenesis in a mouse model. J Clin Invest 2004;114:330-8.

31 Wang X-L, Zhao Y-S, Hu M-Y, et al. Umbilical cord blood cells regulate endogenous neural stem cell proliferation via hedgehog signaling in hypoxic ischemic neonatal rats. Brain Res 2013;1518:26-35.

32 Paczkowska E, Kaczyńska K, Pius-Sadowska E, et al. Humoral activity of cord blood-derived stem/progenitor cells: implications for 
stem cell-based adjuvant therapy of neurodegenerative disorders. PLoS One 2014;8:e83833.

33 Andres RH, Horie N, Slikker W, et al. Human neural stem cells enhance structural plasticity and axonal transport in the ischaemic brain. Brain 2011;134:1777-89.

34 Rumajogee P, Altamentova S, Li L, et al. Exogenous neural precursor cell transplantation results in structural and functional recovery in a hypoxic-ischemic hemiplegic mouse model. eNeuro 2018;5. doi:10.1523/ENEURO.0369-18.2018. [Epub ahead of print: 04 Dec 2018].

35 Gluckman E. History of cord blood transplantation. Bone Marrow Transplant 2009;44:621-6.

36 Ruiz-Delgado GJ, Mancías-Guerra C, Tamez-Gómez EL, et al. Dimethyl sulfoxide-induced toxicity in cord blood stem cell transplantation: report of three cases and review of the literature. Acta Haematol 2009;122:1-5.

37 Yanagisawa R, Abe S, Fujihara I, et al. Transfusion-Associated hypoxemia in pediatric patients with solid tumors after autologous peripheral blood stem cell transplantation. Transfus Apher Sci 2017:56:744-7.

38 Fischer UM, Harting MT, Jimenez F, et al. Pulmonary passage is a major obstacle for intravenous stem cell delivery: the pulmonary firstpass effect. Stem Cells Dev 2009;18:683-92.
39 Petersen A, Seear K, Munsie M. Therapeutic journeys: the hopeful travails of stem cell tourists. Sociol Health IIIn 2014;36:670-85.

40 Novak I, Walker K, Hunt RW, et al. Concise review: stem cel interventions for people with cerebral palsy: systematic review with meta-analysis. Stem Cells Transl Med 2016;5:1014-25.

41 Ketelaar M, Vermeer A, Helders PJ. Functional motor abilities of children with cerebral palsy: a systematic literature review of assessment measures. Clin Rehabil 1998;12:369-80.

42 Thorley M, Lannin N, Cusick A, et al. Reliability of the quality of upper extremity skills test for children with cerebral palsy aged 2 to 12 years. Phys Occup Ther Pediatr 2012;32:4-21.

43 Bruno DL, Ganesamoorthy D, Thorne NP, et al. Use of copy number deletion polymorphisms to assess DNA chimerism. Clin Chem 2014;60:1105-14.

44 Mclntyre S, Novak I, Cusick A. Consensus research priorities for cerebral palsy: a Delphi survey of consumers, researchers, and clinicians. Dev Med Child Neurol 2010;52:270-5.

45 Alotaibi M, Long T, Kennedy E, et al. The efficacy of GMFM88 and GMFM-66 to detect changes in gross motor function in children with cerebral palsy (CP): a literature review. Disabil Rehabil 2014;36:617-27.

46 Hickey A, Ziviani J. A review of the quality of upper extremities skills test (QUEST) for children with cerebral palsy. Phys Occup Ther Pediatr 1998;18:123-35. 